\title{
Analisis Sistem Kendali Sendi Exoskeleton Robotik untuk Pola Pergerakan Manusia Normal
}

\author{
Nova Silvia, T. Jhon Warif Hasibuan, Rony Harjon Lumbantobing, Budiana* \\ Politeknik Negeri Batam, Batam, Indonesia \\ *Email: budiana@polibatam.ac.id
}

\begin{abstract}
Abstrak - Salah satu alat yang dapat digunakan untuk membantu pergerakan tubuh manusia adalah dengan menggunakan sendi exoskeleton. Tujuan dari penelitian ini adalah untuk mengaplikasikan Fuzzy Logic Controller (FLC) dengan menggunakan $\mathrm{C \#}$ dalam pengaturan besar torsi yang telah ditentukan dan arah putaran motor ke driver motor, serta mengubah sinyal input berupa sudut fase berjalan menggunakan metode Fuzzy Logic Clasification. Berdasarkan hasil penelitian yang telah dilakukan diperoleh kesimpulan bahwa dengan mengontrol arus yang diberikan sebesar 2215 mA menghasilkan variasi dari tiap fase gaya berjalan sehingga diketahui pola pergerakan manusia. Berdasarkan panjang lengan beban sebesar $40 \mathrm{~cm}$ didapatkan gaya sebesar $5,53 \mathrm{~N}$.
\end{abstract}

Kata kunci: Sensor Intertial Measurement Unit (IMU), Arduino, Motor DC Brushless, FLC

\section{PENDAHULUAN}

Berjalan merupakan Aktivitas gerak tubuh yang dilakukan manusia sehari-hari. Jika aktivitas tersebut terus dilakukan misalnya ketika seseorang sibuk bekerja maka akan menimbulkan kelelahan pada sendi-sendi exoskeleton. Berdasarkan hal tersebut maka untuk mengurangi rasa lelah tersebut dibutuhkan alat berupa prototipe exoskeleton. Penerapan exoskeleton dalam dunia industri bertujuan untuk membantu manusia dalam melakukan aktivitas yang membutuhkan tenaga yang besar, yang pada dasarnya diluar kemampuan manusia seperti mengangkat benda dan memindahkan benda yang berat. Sedangkan dalam dunia medis penerapan exoskeleton digunakan untuk membantu manusia karena kondisi tertentu tidak mampu melakukan aktivitas layaknya manusia normal.

Exoskeleton ini berbentuk prototype ringan yang dapat dikendalikan menggunakan motor listrik serta sensor dari pergerakan otot manusia [1]. Terdapat penelitian tentang exoskeleton mulai dari struktur dan analisis exoskeleton melalui pemodelan sampai dengan pengontrolan manual pada sistem sendi exoskeleton [2]. Selain dari itu, beberapa penelitian yang telah dilakukan diperoleh suatu informasi bahwa exoskeleton berupa prototipe memiliki manfaat bagi manusia sehingga tentu diperlukan suatu penelitian lanjut mengenai gerak berjalan pada manusia [3]. Dalam melakukan gerak berjalan manusia pada hip exoskeleton, tentunya diperlukan suatu sistem yang berguna untuk mengontrol arus dan arah putaran pada motor. Motor yang digunakan berfungsi untuk menggerakkan sendi exoskeleton tersebut. Oleh sebab itu, diperlukaan penelitian yang khusus mengenai sendi exoskeleton yang dapat diaplikasikan pada manusia normal. Dengan metode Fuzzy Logic Controller (FLC) maka akan didapatkan fase-fase berbeda pada saat berjalan, dimana fase ini terdiri atas 7 fase yang meliputi fasa-fasa sebagai berikut loading response, mid stance, terminal stance, pre swing, mid swing, terminal swing, dan heel strike yang disebut Gait Cycle [4]. Metode FLC memiliki kelebihan dibandingkan dengan beberapa metode lainnya yaitu mampu menyesuaikan sistem kendali exoskeleton dengan pola berpikir manusia, dapat mengendalikan arah putaran dan nilai arus sehingga dapat menghasilkan nilai torsi yang diinginkan [5].

\section{Metode PENELITIAN}

Perancangan sistem pembuatan alat terbagi atas 2 bagian pokok, yaitu perancangan perangkat keras dan perancangan perangkat lunak.

\section{A. Perancangan Perangkat Keras}

Dalam perancangan perangkat keras, sistem kendali sendi exoskeleton ini meliputi 3 pembagian, yaitu masukan (input), proses (process), dan keluaran (output). Untuk perangkat keras yang digunakan adalah menggunakan bahan dasar dari aluminium. Alat penggerak yang digunakan adalah motor Brushless Direct Current (BLDC). Gambar 1 adalah diagram blok sistem kerja alat kendali robot exoskeleton. Penjelasan diagram blok sistem kerja alat adalah sebagai berikut:

1) Input

Input pada alat ini Sensor IMU memiliki fungsi untuk mendeteksi pergerakan berjalan dan mengatur nilai torsi yang diinginkan pada motor. 


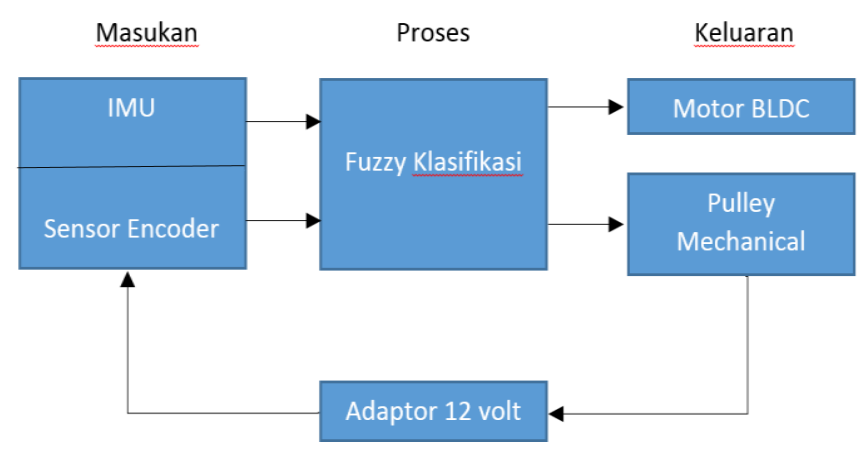

Gambar. 1. Blok sistem kerja alat

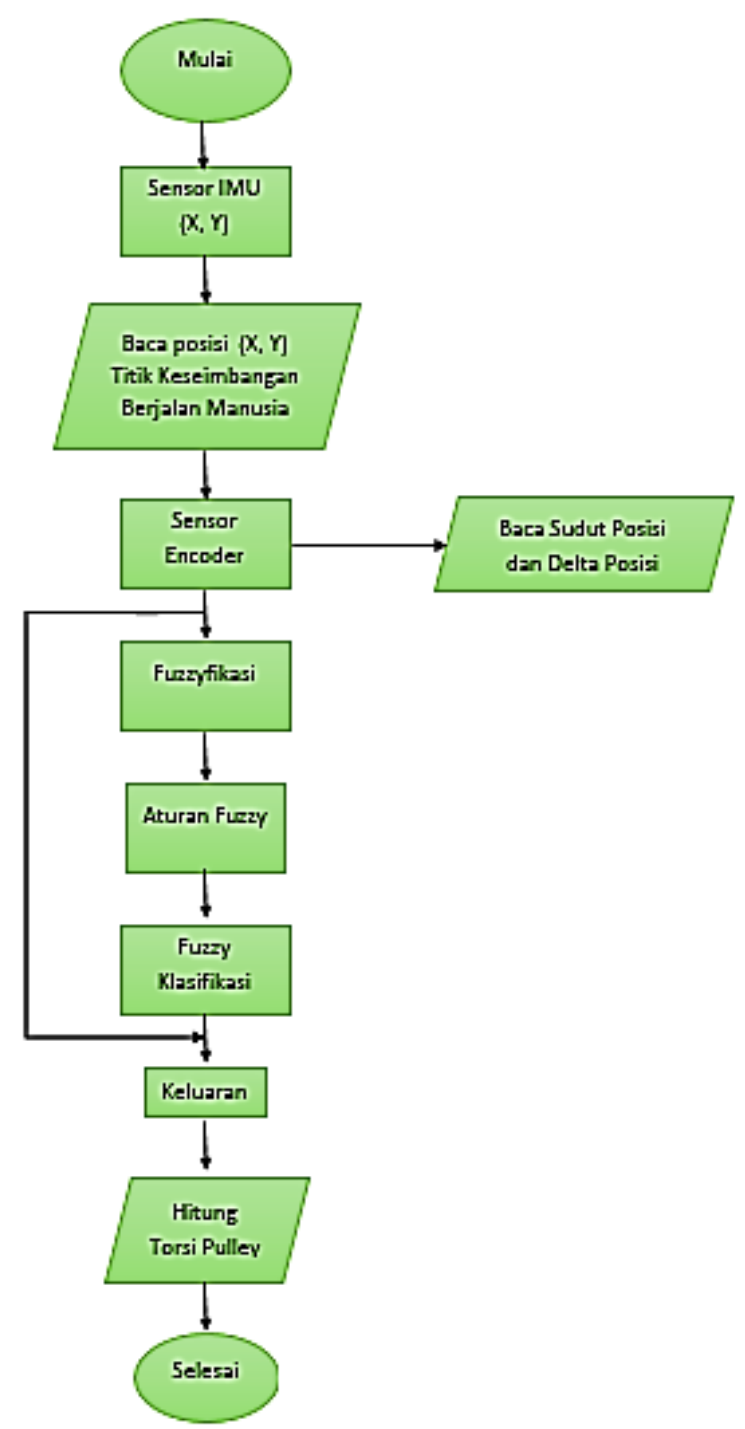

Gambar. 2. Flowchart sistem kendali robot exoskeleton bagian hip

2) Proses

Pada proses ini yang bekerja adalah Peronal Computer (PC) yang berfungsi untuk mengolah data dengan metode FLC yang dikirimkan ke layar monitor PC. Sinyal sensor fase berjalan kemudian diolah dan dikirim ke driver motor untuk mengatur arah dan besar torsi motor.
3) Output

Output pada alat ini adalah berupa arus yang berfungsi untuk mengatur arah dan mendapatkan besar torsi pada motor BLDC. Dengan metode Fuzzy, fase berjalan dibagi menjadi 7 fase yaitu: loading response, mid stance, terminal stance, pre swing, mid swing, terminal swing, dan heel strike.

\section{B. Perancangan Perangkat Lunak}

Perancangan perangkat lunak menggunakan C\#, yang digunakan untuk melihat hasil dari nilai torsi dan arah putaran motor dengan bentuk tabel. Pengguna dapat mengetahui grafik dan nilai tekanan dari alat sehingga, pergerakan motor menunjukkan nilai besar torsi dan arah putaran motor dari alat tersebut. Gambar 2 menjelaskan sistem kendali robot exoskeleton bagian hip.

\section{Pengujian Motor}

Graphical User Interfaces (GUI) yang digunakan di C\# dan pengambilan data dalam menentukan fase gaya berjalan dengan pengujian sudut masing-masing motor ditampilkan pada Gambar 2 dan Gambar 4. Interface ini adalah tempat pengguna mengontrol dan memberikan perintah ke alat (lihat Gambar 3 dan Gambar 5) melalui tombol-tombol yang telah di sediakan. Tampilannya didesain sederhana agar setiap orang dapat dengan mudah memahami dan menggunakan interface ini.

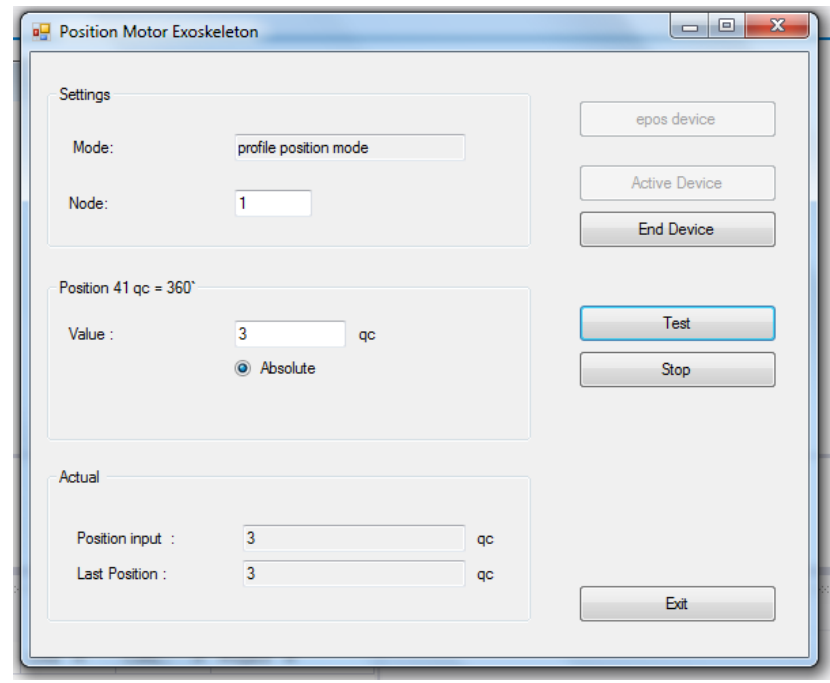

Gambar. 2. Tampilan C\# dengan sudut $0^{\circ}$

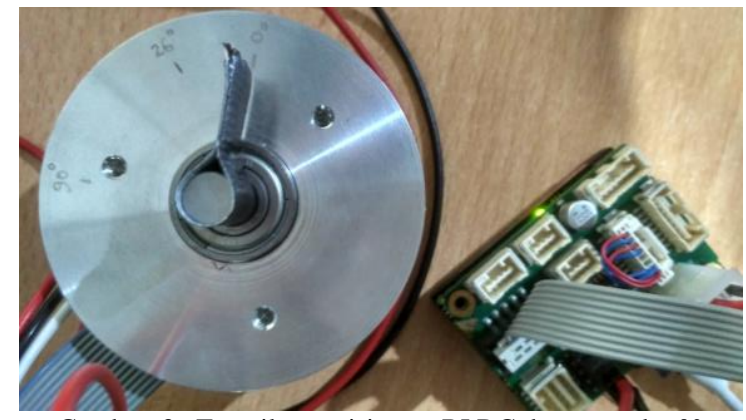

Gambar. 3. Tampilan posisi rotor BLDC dengan sudut $0^{\circ}$ 


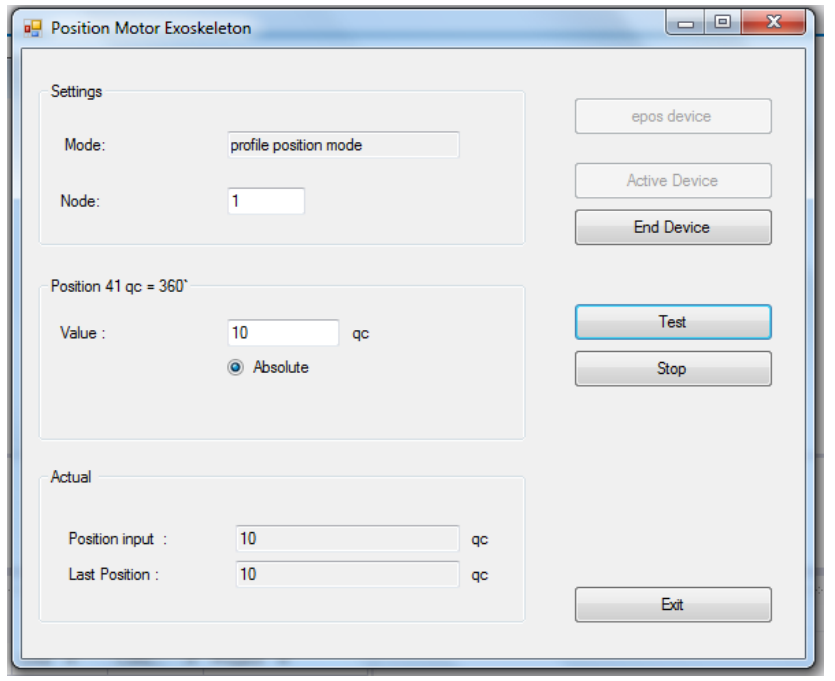

Gambar. 4. Tampilan pada C\# dengan sudut $90^{\circ}$

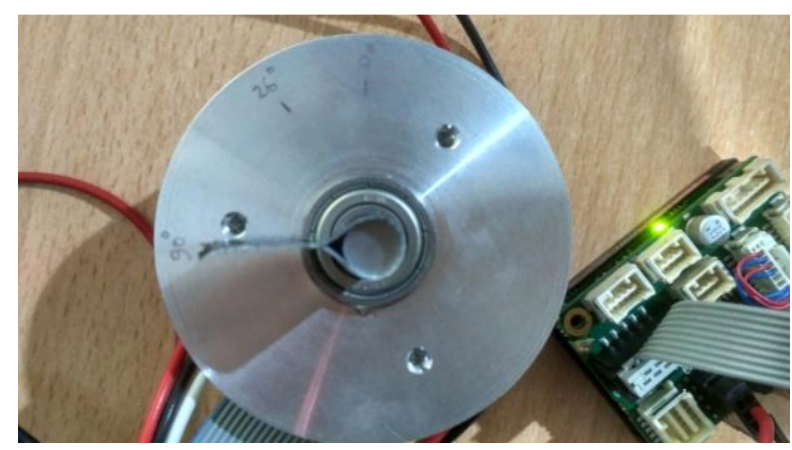

Gambar. 5. Tampilan posisi rotor BLDC dengan sudut $90^{\circ}$

\section{HASIL DAN PEMBAHASAN}

Berdasarkan langkah yang dilakukan dengan menggunakan percobaan pada Fuzzy, klasifikasi yang telah dilakukan akan menghasilkan respon yang berbeda-beda. Respon yang dihasilkan dari pengujian adalah frame gaya berjalan manusia dan arus yang dikontrol pada motor dapat menghasilkan torsi sebagai berikut:

\section{A. Frame Gaya Berjalan Berdasarkan Metode Fuzzy}

Pada percobaan analisis gaya berjalan menggunakan Fuzzy klasifikasi diperoleh hasil frame yang memiliki sudut berbedabeda dapat dilihat pada Gambar 6.

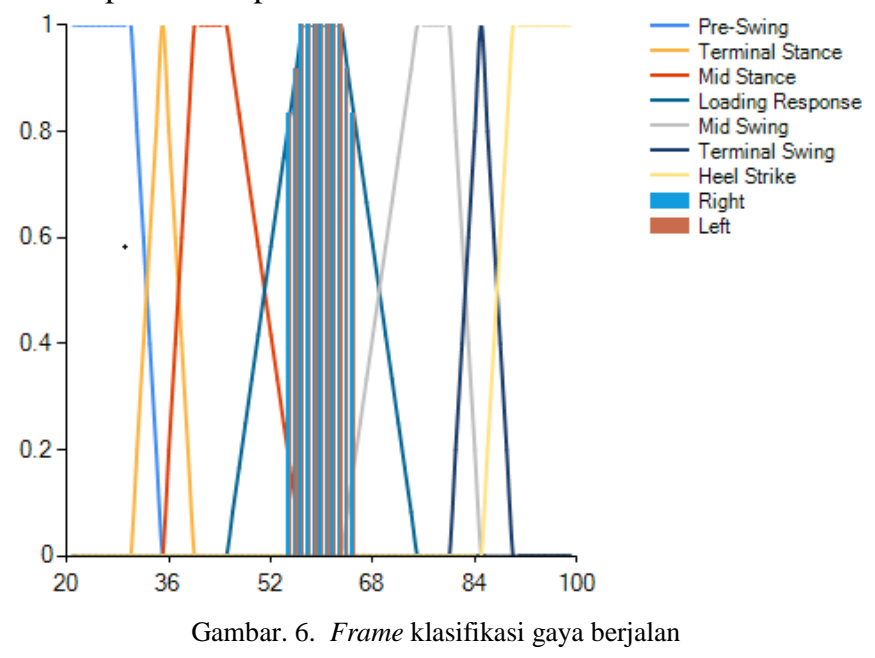

Dapat dilihat pada Gambar 6 bahwa frame terdiri dari 7 fase yaitu Terminal Stance, Pre-swing, , Mid Stance, Loading Resoponse, Mid Swing, Terminal Swing, dan Heel Strike. Tabel I menyajikan data yang dihasilkan dari klasifikasi Fuzzy frame gaya berjalan.

TABLE I

KLASIFIKASI FRAME GAYA BERJALAN MANUSIA

\begin{tabular}{|c|c|c|c|}
\hline $\begin{array}{c}\text { Sudut } \\
\text { Posisi } \\
\text { Kiri }\end{array}$ & $\begin{array}{c}\text { Sudut } \\
\text { Posisi } \\
\text { Kanan }\end{array}$ & $\begin{array}{c}\text { Fase Berjalan } \\
\text { Kaki Kiri }\end{array}$ & $\begin{array}{c}\text { Fase Berjalan Kaki } \\
\text { Kanan }\end{array}$ \\
\hline 2,91 & 6,44 & Loading Response & Loading Response \\
\hline 2,7 & 19,93 & Loading Response & Loading Response \\
\hline$-11,13$ & $-7,49$ & Mid Swing & Mid Stance \\
\hline 0,34 & $-7,98$ & Terminal Swing & Mid Stance \\
\hline 22,69 & $-6,52$ & Mid Swing & Mid Stance \\
\hline 28,61 & $-0,32$ & Loading Response & Mid Stance \\
\hline 28,55 & 11,44 & Terminal Stance & Mid Stance \\
\hline 27,95 & 23,46 & Pre Swing & Loading Response \\
\hline 28,48 & 5,19 & Pre Swing & Mid Swing \\
\hline 27,73 & $-2,85$ & Pre Swing & Mid Swing \\
\hline 26,15 & $-18,31$ & Pre Swing & Mid Swing \\
\hline$-5,97$ & $-28,32$ & Pre Swing & Loading Response \\
\hline$-16,29$ & $-31,72$ & Terminal Stance & Mid Stance \\
\hline$-29,83$ & $-32,61$ & Mid Swing & Pre-Swing \\
\hline$-30,23$ & $-33,13$ & Mid Swing & Pre-Swing \\
\hline 5,47 & $-32,68$ & Heel Strike & Pre-Swing \\
\hline 9,9 & $-30,16$ & Heel Strike & Pre-Swing \\
\hline 5,73 & 1,37 & Mid Stance & Pre-Swing \\
\hline 10,55 & 1,91 & Mid Stance & Pre-Swing \\
\hline 14,42 & 0,15 & Mid Stance & Loading Response \\
\hline 32,02 & 1,39 & Pre Swing & Loading Response \\
\hline 31,35 & $-0,33$ & Pre Swing & Loading Response \\
\hline$-11,78$ & 0,49 & Mid Swing & Loading Response \\
\hline 10,44 & 27,03 & Loading Response & Loading Response \\
\hline & & & \\
\hline
\end{tabular}
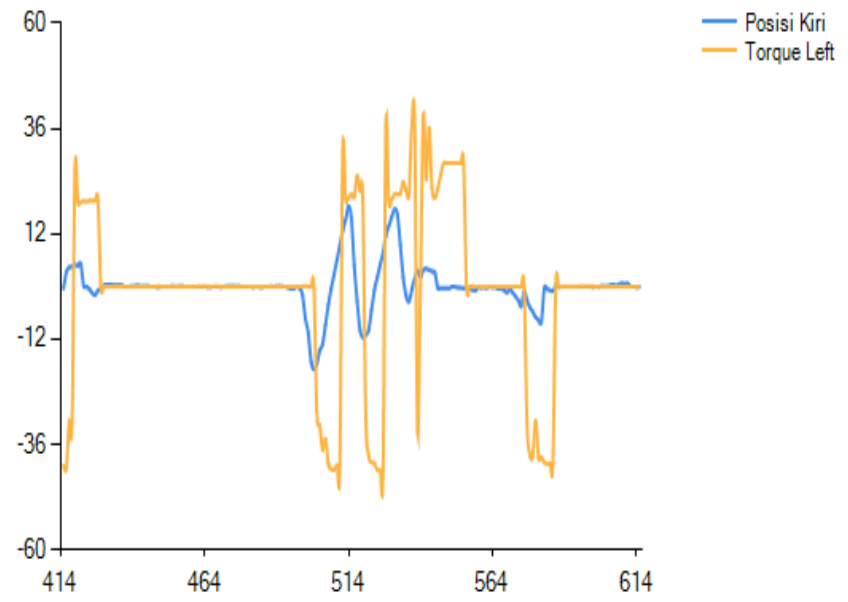

Gambar. 7. Respon motor dengan arus $2215 \mathrm{~mA}$ pada motor kiri 


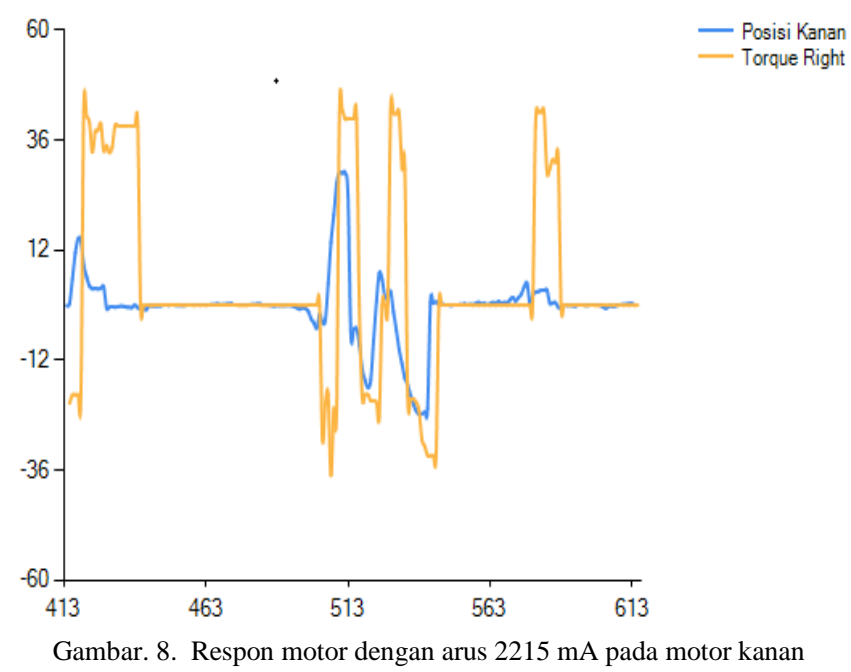

B. Pengontrolan Motor untuk Mendapatkan Besar Torsi

Untuk mengetahui besar torsi, maka dilakukan percobaan pada kendali arus motor BLDC dengan arus maksimal 4430 $\mathrm{mA}$. Dari data yang dihasilkan, kita dapat menghitung jumlah torsi yang digunakan pada proses berjalan dengan identifikasi persamaan (1). Pengujian motor BLDC dengan arus $2215 \mathrm{~mA}$, dihasilkan data pada Gambar 7 dan Gambar 8.

$$
\text { torsi }=\frac{\text { input_arus }}{\text { arus_max_continous }} \times \text { torsi_maximum }
$$

Dengan referensi pada Motor DC Brushless yang memiliki arus maximum sebesar $4430 \mathrm{~mA}$ dan nilai torsi maximum sebesar $227 \mathrm{mNm}$, maka dapat dilakukan perhitungan dengan hasil yang dapat dilihat pada Tabel II.

Perhitungan gaya yang diberikan untuk pola pergerakan manusia normal dapat diketahui melaui perhitungan rumus torsi. Jika besaran torsi yang diberikan (torsi) adalah sebagai $2215 \mathrm{mNm}$ dan panjang lengan hip exoskeleteon $(r)$ sebesar 40 $\mathrm{cm}$, maka didapatkan hasil analisa gaya pola pergerakkan manusia sebesar 5.53 N. Perhitungannya adalah sebagai berikut:

$$
\begin{aligned}
& \text { torsi }=F \times r \\
& 2,215=F \times 0,4 \\
& F=5,53 N
\end{aligned}
$$

\section{KESIMPULAN}

Perancangan alat menggunakan metode FLC yang dirancang mampu menampilkan klasifikasi frame gaya berjalan dengan 7 pola berjalan manusia. Nilai Maksimum torsi kaki kiri yang dihasilkan adalah sebesar $129,11 \mathrm{mNm}$ sedangkan nilai torsi kaki kanan adalah sebesar 193, $83 \mathrm{mNm}$. Gaya yang dihasilkan adalah sebesar 5,53 N, yang diperoleh dengan menggunakan panjang lengan $40 \mathrm{~cm}$ dan arus yang dikontrol bernilai 2215 $\mathrm{mA}$.

\section{UCAPAN TERIMA KASIH}

Ucapan terima kasih diberikan kepada Kementerian Riset, Teknologi dan Pendidikan Tinggi Republik Indonesia yang telah memberikan dukungan finansial melalui Program
Kreativitas Mahasiswa Penelitian (PKM-P), juga kepada

\begin{tabular}{|c|c|c|c|}
\hline \multicolumn{4}{|c|}{ HASIL PENGONTROLAN ARUS 2215 MA } \\
\hline $\begin{array}{l}\text { Arus Kaki } \\
\text { Kiri (mA) }\end{array}$ & $\begin{array}{c}\text { Arus Kaki } \\
\text { Kanan (mA) }\end{array}$ & $\begin{array}{c}\text { Torsi Kaki } \\
\text { Kiri }(\mathbf{m N m})\end{array}$ & $\begin{array}{c}\text { Torsi Kaki } \\
\text { Kanan }(\mathbf{m N m})\end{array}$ \\
\hline$-1946,8$ & $-1946,8$ & 126,92 & $-151,00$ \\
\hline 2096,28 & 2096,28 & $-192,94$ & 158,66 \\
\hline-952 & -952 & 128,68 & $-100,02$ \\
\hline$-923,2$ & $-923,2$ & 128,68 & $-98,55$ \\
\hline$-996,8$ & $-996,8$ & 107,50 & $-102,32$ \\
\hline$-1012,8$ & $-1012,8$ & 107,50 & $-103,14$ \\
\hline$-908,4$ & $-908,4$ & $-193,46$ & $-97,79$ \\
\hline$-908,4$ & $-908,4$ & $-143,43$ & $-97,79$ \\
\hline 2063,72 & 2063,72 & $-157,99$ & 208,23 \\
\hline 1782,62 & 1782,62 & $-157,99$ & 193,83 \\
\hline 1782,62 & 1782,62 & $-161,19$ & 193,83 \\
\hline-1410 & -1410 & $-176,61$ & $-174,73$ \\
\hline-1194 & -1194 & $-197,87$ & $-112,42$ \\
\hline$-1093,2$ & $-1093,2$ & 129,11 & $-107,26$ \\
\hline$-1449,2$ & $-449,2$ & 129,11 & $-176,74$ \\
\hline$-1644,4$ & $-1644,4$ & 129,11 & $-186,74$ \\
\hline$-1644,4$ & $-1644,4$ & 129,11 & $-186,74$ \\
\hline$-1644,4$ & $-1644,4$ & 129,11 & $-186,74$ \\
\hline$-1644,4$ & $-1644,4$ & $-214,31$ & $-186,74$ \\
\hline$-1644,4$ & $-1644,4$ & $-214,25$ & $-186,74$ \\
\hline$-1644,4$ & $-1644,4$ & $-196,43$ & $-186,74$ \\
\hline$-1644,4$ & $-1644,4$ & $-196,43$ & $-186,74$ \\
\hline$-946,8$ & $-946,8$ & $-200,08$ & $-151,00$ \\
\hline-444 & -444 & 100,04 & $-176,48$ \\
\hline
\end{tabular}
Hendawan Soebakti, M.T., Susanto, M.Sc., dan Daniel Sutopo Pamungkas, Ph.D.

TABLE II

\section{REFERENSI}

[1] Zheng, E. et al.2017'Gait phase estimation based on noncontact capacitive sensing and adaptive oscillators', IEEE Transactions on Biomedical Engineering, 64(10) ,2419-2430.

[2] Sado F, Y. H. 2018 'Exoskeleton robot control for synchronous walking assistance in repetitive manual handling works based on dual unscented Kalman filter'. Department of Mechanical Engineering, Faculity of Engineering, University of Malaysia, Kuala Lumpur, Malaysia, 13(7) 1-36.

[3] Gopura, R. A. 2009 'Development and Control of UpperLimb Exoskeleton Robots'. A dissertation submitted in partial fulfillment of the requirements for the Doctor of Philosophy degree in Robotics and Intelligent Systems, Department of Advanced Systems Control Engineering, Graduate School of Science and Engineering, Saga University, Japan(September), 3-79.

[4] Aguirre-Ollinger, G.,Nagarajan, U., and Goswami, A. 2016'An admittance shaping controller for exoskeleton assistance of the lower extremities', Autonomous Robots, 40(4), 701-728.

[5] Yulianta, A. D., Hadi, S. P. and Suharyanto $2015^{\circ}$ Pengendalian Kecepatan Motor Brushless dc Menggunakan Metode Logika Fuzzy', Jurnal Sains, Teknologi dan Industri, 8(1), 1-9. 